\title{
Impact of Pidgin English on the Effective Learning of English Language among Junior Secondary School Students in Port Harcourt
}

\author{
Obisike Iheanyi Osondu Ph.D. \\ School Of Foundation Studies \\ Rivers State College of Health Science \& Technology \\ Port Harcourt, Nigeria \\ Nwala Michael Alozie Ph.D \\ Department Of English Studies \\ University of Port Harcourt \\ Choba, Port Harcourt, Nigeria \\ Mbong Joy Etaruwak \\ Faculty of Education \\ National Open University of Nigeria \\ Abuja, Nigeria
}

\begin{abstract}
This study investigated mother tongue interference among junior secondary school students in Port Harcourt Local Government Area of Rivers State, Nigeria where Pidgin English is mostly used in communication and serves as the L1. It focused on "transfer of rules" errors. The study adopted a quantitative research design with a sample size of 120 students randomly selected from four schools in the study area. The questionnaire was used as the instrument for data collection. Frequencies, percentages and mean scores were used to analyse the data. Any item that scores above 50\% was considered valid. The major findings show that the students had "Transfer of Rules" Error on Phonology; they had $54.4 \%$ incorrect responses on the realization of $/ \theta /$ and $/ z /$. The respondents also had difficulty in the correct usage of the morpheme "er" in generating words; they had an overall mean score of $60.4 \%$ under incorrect responses. The study therefore recommended adequate and constant practice so as to overcome negative mother tongue transfer.
\end{abstract}

Keywords: Pidgin English, mother tongue, target language, interference, language, communication, interaction; deviation

\section{Introduction}

Language is the hallmark of creation and human existence; every human activity is built on communication hence the inevitability of language in human relationships. According to Nwala and Obisike (2014), language is a system of producing meaningful and coherent expressions by a speech community for communication purposes. They further explain that if the network of expressions is distinct, such network is a language of its own. Language is an important tool that enhances human communication and interaction. It is a vital instrument in cultural transmission and preservation of a social group. It is in a fundamental sense, a crucial tool in the preservation and propagation of the human species. The English language is the official and native language of Britain, Ireland, North America, Australia, America and most of the British colonies. According to Gooden (2011, p.2), "of all the languages which had their probable origins in 'one language ... one speech' many millennia ago, the most successful and the most widely spoken - up to the present day - is English". He further states that 380-million people speak English as a first language and some 600-million as their second language, while about one-billion persons are taught of learning it, including Nigerians. Based on this overwhelming population using the English language, Gooden concludes that English is the foremost international language in communications and therefore may be the first universal language of this era

The English language being the official language for the British colonies of which Nigeria is among makes it her second language, existing alongside over 450 languages in the country. In the case of Rivers State, 17 languages exist (Ndimele, 2011). This multilingual situation of Rivers State has made possible inherent challenges of multilingualism in the teaching-learning of the English language in schools in the state. There are four dominant languages, namely: Ikwerre, Igbo, Pidgin (English) and English spoken in the city. Pidgin English appears to be the most dominant because of the metropolitan nature of the area. 
Pidgin English is a corrupt version of the language used as a means of communication among various people who speak different languages. Consequently, the learning of each of the languages is affected negatively or positively by others. The negative form of it is called interference which has been defined by Lehiste (1988, p.1) as: "deviations from the norms of either language that occur in the speech of bilinguals as a result of their familiarity with more than one language". Such interference could be traced to one's first language, and it is called mother tongue interference. Mother tongue is explicitly defined by Richards and Schmidt (2010, p.377) as "a first language which is acquired at home." This study considers Pidgin English as the L1 (first language/mother tongue), while English Language is the L2 (second language/target language). This position agrees with Richards and Schmidt (2010, p.438) who state that the "Tok Pisin in Papua New Guinea and Nigerian Pidgin English in West Africa, ... are spoken by some people in their community as first or primary language".

Pidgin English has continued to fill the gap in communication created by Standard English among Nigerians of diverse linguistic and educational backgrounds. It is used by politicians during campaigns because it is the language of the masses; government officials use it to address rural dwellers during advocacy visits; advertisers use it to market products on bill boards and radio/television programmes. Doctors also use it to elicit responses from illiterate patients; pastors use it to preach in churches. That the use of Pidgin English has spread through every Nigerian linguistic space is to state the obvious. According to Azubuike (2013, para 3) " Pidgin is commonly used as lingua franca among educated and illiterate Nigerians, given the multi-ethnic and multi-cultural nature of the society. This is further reenforced by the nation's high illiteracy levels that varies from one section of the country to another, and even within each section of the society."

Obviously, Pidgin English (as the mother tongue in this case) would interfere with the learning of English Language. Interestingly, the English language is a language of communication among the people with different cultures as it is in Nigeria. It is also the language of computers that help people to communicate with the people around the world through internet technology. Several factors affect the learning and proficiency of a second language. Among them are the nature and structure of the first language, culture, environment, age, method of acquisition and the amount of efforts invested. The degree of differences and similarity between the mother tongue and the target language are important factors in the learning of a second language. One crucial feature of L2 learning is that the learner has had experience of another language. All these reasons given above could result in interference in the learning of English as a second language. It is important to determine the extent of interference of the experience of Pidgin English as mother tongue by junior secondary school students in the learning of English Language.

\section{Study Area}

Port Harcourt is the capital of Rivers State, Nigeria. It is in the Niger Delta Region of Nigeria. The original indigenes of Port Harcourt are the Ikwerres. They are within the rain forest belt. The blessed geographical location of Port Harcourt has endowed it with strategic position in Rivers State and Nigeria at large. The metropolitan nature of the area made the use of Pidgin English as a means of communication to accommodate different linguistic backgrounds of residents.

\section{Literature Review}

\section{Conceptual Review}

\section{i. Pidgin English}

The word "pidgin" in grammar means a simplified form of a language embellished with expressions from local languages, used for communication between people who do not have a common language. By this process, the original language is corrupted by new users who are largely illiterate. Etymologically, "pidgin" is a Chinese word for "business" which indicates relationship between pidgin and trade (Gooden, 2009). According to him, Pidgin English is linked to slave trade, specifically in the transport of West Africans across the Atlantic who were taken from different tribes. Before the movements, the Europeans ensured that the slaves were grouped in a manner that they were incapable of speaking the same language or understood themselves. This ploy prevented slaves from causing trouble during traffic. Pidgin was the option left for communication. Pidgin English therefore developed for two reasons: the sailors needed it to communicate with slaves, and slaves needed it to communicate with each other.

Pidgin English "then spread round the world, following sailors and trade-routes. A distinctive branch of it is found in Papua New Guinea and its nearby islands" (Gooden, 2015, p. 175 -176). According to him, pidgin language is not peculiar to English; there is Pidgin French. We also have Pidgin Portuguese, etc. There are several arguments on what actually constitutes Pidgin English in Nigeria. Elugbe (2015) states that Bamgbose (1995) expressly classified the varieties of English in Nigeria, identifying Nigerian Pidgin as a strand of Contact English, and Broken English as another form. 
Elugbe sees Nigerian Pidgin as being different from other forms of English in Nigeria such as language of "Wakabout" and the language of a soap opera called "Masquerade" as used by Chief Zebrudiah Okorigwe Nwobo (its lead character). In this work, we lean on the position of Elugbe (2015) to state that our pidgin of discussion is not "Broken English (BE)" but Nigerian Pidgin (NP). For us, BE comes as a result of attempts by semi-illiterate persons to express themselves in "Standard English" which is botched up by wrong manipulation of words. On the other hand, users of NP do not aspire to use Standard English expressions. This explains why NP is used by both educated and uneducated Nigerians. The expression: "How is you?" is popularly used by Zebrudiah and Jennifer (a popular actress in Nigerian movies). It is a good example of Broken English, and certainly not an example of Nigerian Pidgin. Its equivalent in NP is "How you de?"

Elugbe goes further to state that NP is gradually metamorphosing into a language having stabilized with relatively simple structural characteristics. Gooden (2009) also describes a Pidgin language as being simplified by comparison with its source language. "It may dispense with word endings or drop certain words altogether, such as pronouns or the definite and indefinite articles. It will be simple, therefore, but it is not the equivalent of baby-talk" (p. 176).

\section{ii. Mother Tongue Interference}

A lot of views have arisen with respect to what causes mother-tongue interference. Mother-tongue interference is the linguistic interference of a child's first language caused by the absence of linguistics features of the target language in his mother tongue. Mother tongue or first language is the language which a group of people considered to be the inhabitants of an area, acquire in their early years and which normally becomes their natural instrument of thought, communication and identification.

First language or mother tongue (LI/MT) is the first language a child picks up. It is not learnt but acquired. It is the language that encodes early concepts of the child. Mother tongue speakers are regarded as 'A' speaker of that very language. It is also seen as "one's native language" (Stevenson \& Waite, 2011). In some countries such as Kenya and India "mother tongue" is used to indicate the language of one's ethnic group, in both common and journalistic parlance.

Also in Singapore, "mother tongue" refers to the language of one's ethnic group regardless of actual proficiency, while the "first language" refers to the English language, which is the language of instruction in government schools and as a working language despite it not being a native tongue for most Singaporeans. In this research work mother tongue will be regarded as the language of one's ( students' also/or child's) environment.

\section{Empirical Review}

In a paper titled: Phonological Transfer and Universal Grammar: Evidence from Arabic, Shormani and AlSohbani (2015) provided empirical evidence in support of the availability of transfer and UG in L2 acquisition, specifically, concerning acquiring phonology. 20 students majoring in English were selected randomly from two classes, namely, first and third, i.e. the same students in two different years/levels. Four phonological categories were examined, namely, consonants, vowels, stress and consonant clustering. The results indicated that both UG and transfer contribute almost equally in L2 phonology acquisition.

Similarly, Koźbiat (2011) did a work on phonological error mapping of English - Polish contrastive analysis. The paper examined the phenomenon of Phonological Error Mapping, from Polish (the participants' mother language, thereafter L1) to English (the participants' target language, thereafter L2). Phonological Error Mapping could be explained as transfer of certain phonological rules (e.g. difference in vowel lengths or word/sentence stress allocation) from L1 to L2. This transfer can occur when a learner lacks sufficient knowledge of L2 and tries to fill the gap with L1 rules, a 'positive' transfer, which takes place when L1 and L2 have something in common and a learner can easily reassign information from L1 to L2. However, this paper showed that in many cases where transfer was expected, it did not occur. Similarly, there were some examples where participants showed tendencies to use transfer against their knowledge of L2.

In another work titled "Mother Tongue Interference on the Spoken English of Berom Speaking Students in Plateau State Polytechnic". Marcus (2018) investigated the influence of mother tongue interference on the pronunciation of English sounds among Berom language speakers in Plateau State Polytechnic, Barkin Ladi, Nigeria. The study compared the segmental phonemes of English and Berom languages and showed how the differences cause problem in the spoken English of the Berom students. The study also attempted to identify the sounds of English which are the most affected by the sounds of Berom, and, suggested activities that will help reduce this influence.

The work of Labiba (2015) revealed that the Hausa learners of English as a second language experience difficulty in tense formation in English. Hausa tenses remain the same unlike English language where different tenses have different morphological forms, thereby causing negative transfer. The Hausa native speaker gets confused when using possessive pronouns in his English construction. 
This is because the use of possessive verbs (have and has) differs in English language. "Have" is used for first person singular, second person singular, first person plural, second person plural and third person plural. "Has" on the other hand is use for third person singular only, but in Hausa language, these differences do not occur. The Hausa native speaker may say, He have a book instead of He has a book. I has a bag instead of I have a bag. This interference occurs to the Hausa native speakers because in Hausa the word 'da' stands for both 'have' and 'has'.

Mahe and Adegboye (2017) did a work on mother tongue interference titled "Hausa Interference on English Language Usage: The Case of Prepositions in Some Selected Schools in Bauchi State". The study investigated how the use of prepositions in Hausa affected the use of English. A preposition is a word that expresses the relationship of one word with another. But people tend to misuse the use of these prepositions. This is because of the influence of mother tongue interference (Hausa) when speaking English as a second language. It investigated the errors committed by Hausa native students on the use of prepositions. As regards to the findings of this study, it is pertinent to note that, the main cause of errors are overgeneralization, incomplete application of rules, false concept hypothesized and, ignorance of rule restriction errors such as over-generalization. This is why the result of the findings showed high percentage of errors committed by students on the use of prepositions. The result of hypotheses tested showed that, the errors committed are due to the interference of the first language Hausa (L1) on English (L2). In the research, it is concluded that the type of error committed by a student is dependent on the school attended. The errors committed by the private schools students were not as much as the errors committed by the public school students. This is because in the private schools they employed graduate English teachers to teach English Language, but in public schools, according to the biodata of the teachers, anyone, (teacher) as far as he can speak the language, can become an English teacher.

Finally, Idris (2016) worked on interference in the use of English question tags among Nigeria Certificate in Education Hausa students in Federal College of Education, Zaria. It aimed at examining the problems in the use of the English question tags as employed by the Hausa learners of English as a second language, that is, the target population caused by the first language in the formation processes and use of the English question tags by looking at the form, structure and meaning of each. Illustrations of some of the problems identified are, overgeneralization, generalization, learners' induced rules, interference of the learner's mother language, learner's age, learner's psychological attitude and the insufficient language knowledge of English question tags. The descriptive survey design was adopted for the study. Qualitative method of data collection and analysis were used. The tools for the collection included test frame and assignment which the target population (sampled Hausa NCE 1-3) did (answered the questions on both the test and the assignment).The study revealed that the Hausa learners of English as a second language have a peculiar problem of overgeneralization, inducing their rules informing and using English question tags. It also revealed that the greater the difference between the two languages the more negative the effects of the interference are likely to be. The study revealed that the usage of the English question tags was generally affected by the age of the Hausa learners of English as a second language and females often than not use English question tags more than their male counterparts. It further revealed that the youths mainly employed the use of the invariant question tags because it is fashionable coupled with its being handy to use than the canonical type. Finally, it showed that the usage of English question tags was influenced by the first language of the learners of English as the second language

\section{Methodology}

In this paper, we adopted the quantitative design. A quantitative design according to Ndiyo (2015) is a scientific way of investigating phenomena that are amenable to empirical measurement and verification. It involves investigating variables that can be assigned figures or values and which can be empirically observed, measured and verified. To get data, a questionnaire centred on the three research question was administered on the sample size of 120 students randomly selected from four schools in the study area, while frequencies, percentages and mean scores were used to analyse the data.

\section{Analysis}

Analysis of data was based on the research questions. Quantitative information was organized, coded and summarized manually. The analyzed data was summarized using descriptive statistics such as frequencies, percentages and mean scores and presented using tables. Any item that scores above 50\% was considered valid, and the same criterion goes to sections through their overall mean scores.

Research question 1: What percentage of the junior secondary school students in Port Harcourt Local Government Area has "transfer of rules" errors on phonology? 
Table 1a:"Transfer of Rules" Error in the Pronunciation of $/ \boldsymbol{\theta} /$

\begin{tabular}{llllll}
\multirow{2}{*}{ S/N } & \multirow{2}{*}{ ITEM } & \multicolumn{2}{c}{ CORRECT RESPONSE } & \multicolumn{2}{c}{ INCORRECT RESPONSE } \\
& & Frequency & $\%$ & Frequency & $\%$ \\
\hline 1 & Thin & 46 & 38.3 & 74 & 61.7 \\
2 & Faith & 46 & 38.3 & 74 & 61.7 \\
3 & Death & 54 & 45.0 & 66 & 55.0 \\
4 & Throat & 72 & 60.0 & 48 & 40.0 \\
5 & Growth & 52 & 43.3 & 68 & 56.7 \\
\hline & Mean & 54 & 45.0 & 66 & 55.0 \\
\hline
\end{tabular}

Table 1a above shows the respondents' performance in pronouncing the voiceless dental fricative / $\boldsymbol{\theta} /$ as represented by the letters "th". The respondents had $60 \%$ correct response on item 4 (throat), that is, frequency of 72 . The rest items got incorrect responses having scored below 50\%. The mean scores for correct response and incorrect response are $45.0 \%$ and $55.0 \%$ respectively.

\begin{tabular}{llllll}
\multirow{2}{*}{ S/N } & \multirow{2}{*}{ ITEM } & \multicolumn{2}{c}{ Table 1b: “Transfer of Rules" Error in the Pronunciation of $/ \mathbf{z} /$} \\
& & \multicolumn{2}{c}{ CORRECT RESPONSE } & \multicolumn{2}{c}{ INCORRECT RESPONSE } \\
& & Frequency & $\%$ & Frequency & $\%$ \\
\hline 1 & Ones & 52 & 43.3 & 68 & 56.7 \\
2 & Roses & 56 & 46.7 & 64 & 53.3 \\
3 & Plays & 48 & 40.0 & 72 & 60.0 \\
4 & Knees & 62 & 51.7 & 58 & 48.3 \\
5 & Boys & 60 & 50.0 & 60 & 50.0 \\
\hline & Mean & 55.6 & 46.3 & 64.4 & 53.7 \\
\hline
\end{tabular}

Table $1 \mathrm{~b}$ above shows the respondents' performance in pronouncing the voiced alveolar fricative /z/as represented by the letter "s". The respondents had $51.7 \%$ correct responses on item 4 (knees), that is, frequency of 62 , and also equal percentage (of 50\%) on item 5 (boys). The rest items got incorrect responses having scored below 50\%. The mean scores for correct responses and incorrect responses are $46.3 \%$ and $53.7 \%$ respectively

\begin{tabular}{|c|c|c|c|c|c|}
\hline \multirow{3}{*}{$\mathrm{S} / \mathrm{N}$} & able 1c:0 & Mean of "s & nster of Ru & tror in PI & \\
\hline & \multirow[t]{2}{*}{ ITEM } & \multicolumn{2}{|c|}{ CORRECT RESPONSE } & \multicolumn{2}{|c|}{ INCORRECT RESPONSE } \\
\hline & & F (Mean) & $\%$ (Mean) & F (Mean) & $\%$ (Mean) \\
\hline 1 & Pronunciation of $/ \boldsymbol{\theta} /$ & 54 & 45.0 & 66 & 55.0 \\
\hline 2 & Pronunciation of $/ \mathbf{z} /$ & 55.6 & 46.3 & 64.4 & 53.7 \\
\hline & Overall Mean & 54.8 & 45.6 & 65.2 & 54.4 \\
\hline
\end{tabular}

The above table is a summary of tables $1 \mathrm{a}$ and $1 \mathrm{~b}$, using their mean scores that emanated from the correct responses and incorrect responses categories. The table shows overall mean of $45.6 \%$ for correct responses and $54.4 \%$ for incorrect responses.

Research question 2: What percentage of the junior secondary school students in Port Harcourt Local Government Area has "transfer of rules" errors in morphology?

Table 4: "Transfer of Rules" Errors in Morphology (application of the morpheme "er"

\begin{tabular}{llllll} 
S/N & \multirow{2}{*}{ ITEM } & \multicolumn{2}{c}{ CORRECT RESPONSE } & \multicolumn{2}{c}{ INCORRECT RESPONSE } \\
& & Frequency & $\%$ & Frequency & $\%$ \\
\hline 1 & Cooker/Cook & 54 & 45.0 & 66 & 55.0 \\
2 & Cheater/Cheat & 40 & 33.3 & 80 & 66.7 \\
3 & Sponsorer/Sponsor & 22 & 18.3 & 98 & 81.7 \\
4 & Creater/Creator & 40 & 33.3 & 80 & 66.7 \\
5 & Waiter/Waitress & 82 & 68.3 & 38 & 31.7 \\
\hline & Mean & 47.6 & 39.6 & 72.4 & 60.4 \\
\hline
\end{tabular}


Table 2 above shows the respondents' performance in the correct usage of the morpheme "er" in generating words. 98 respondents, giving $81.7 \%$ had incorrect responses on item 3 (sponsorer/sponsor). The table also shows that the respondents did well on item 5 (waiter/waitress) having scored 68.3 correct responses. The mean scores for correct responses and incorrect responses are $39.6 \%$ and $60.4 \%$ respectively.

Research question 3: What percentage of the junior secondary school students in Port Harcourt Local Government Area has "transfer of rules" errors in syntax?

Table 5: "Transfer of Rules" Errors in Syntax (have/has)

\begin{tabular}{|l|l|l|l|l|l|}
\hline $\begin{array}{l}\text { S/ } \\
\text { N }\end{array}$ & SENTENCE & \multicolumn{3}{|l|}{ CORRECT RESPONSE } & \multicolumn{2}{l|}{$\begin{array}{l}\text { INCORRECT } \\
\text { RESPONSE }\end{array}$} \\
\hline & & Frequency & $\%$ & Frequency & $\%$ \\
\hline 1 & The Governor ...... paid salaries. & 94 & 78.3 & 26 & 21.7 \\
\hline 2 & He ..... taken it. & 98 & 81.7 & 22 & 18.3 \\
\hline 3 & $\begin{array}{l}\text { God always ..... good intentions for } \\
\text { us. }\end{array}$ & 4 & 3.3 & 116 & 96.7 \\
\hline 4 & Our boys ....... passed the test. & 66 & 55.0 & 54 & 45.0 \\
\hline 5 & Your friend ...... a new pair of shoes. & 88 & 73.3 & 32 & 26.7 \\
\hline & Overall Mean & $\mathbf{7 0}$ & $\mathbf{5 8 . 3}$ & $\mathbf{5 0}$ & $\mathbf{4 1 . 7}$ \\
\hline
\end{tabular}

Table 3 above shows the respondents' performance in using "have" and its singular form, "has". The usage here is based on "Subject-Verb Agreement". The respondents had over 50\% correct responses on all the items except item 3 which got 3.3\%. The mean scores for correct responses and incorrect responses are $58.3 \%$ and $41.7 \%$ respectively.

\section{Discussion of Findings}

Based on the findings, the respondents' performance in pronouncing the voiceless dental fricative / $\boldsymbol{\theta} /$ as represented by the letters "th" yielded 55\% under incorrect responses. This is an indication that Pidgin English as their first language impacted negatively on the acquisition of English as a second language. This is not surprising as users of Pidgin English had shown, in pronunciation, the difference between phonemes /t/ and / / / as represented in words such as "tin" and "thin." Table $1 \mathrm{~b}$ also showed that the respondents failed in pronouncing the voiced alveolar fricative /z/as represented by the letter "s". The respondents had $53.7 \%$ overall mean score for incorrect responses, an indication of lack of adequate knowledge of English consonant sounds. The overall mean scores for the phonology section are $45.6 \%$ for correct responses and $54.4 \%$ for incorrect responses. $54 \%$ is above the criterion percent for a valid item. This means that the respondents should be engaged adequately to learn phonetics in English having learnt Pidgin English as their first language with its obvious negative transfer. The findings here are consistent with the positions of Shormani and AlSohbani (2015) and Marcus (2018).

It was observed from Table 2 that the respondents' performance in the correct usage of the morpheme "er" in generating words yielded $60.4 \%$ as overall mean for incorrect responses, an indication that Pidgin English had a negative impact on their learning of English. 98 respondents, giving 81.7\% had incorrect response on item 3 (sponsorer/sponsor). This is not surprising because most transfer errors found in a target language are as a result of over generalization of rules. It is possible that the respondents may have over generalized the application of "er". Mahe and Adegboye (2017) had similar experience in their work; they noted that the main cause of errors was overgeneralization, incomplete application of rules, false concept hypothesized and, ignorance of rule restriction errors such as overgeneralization.

Table 3 above shows the respondents" performance in using "have" and its singular form, "has". The usage here is based on "Subject-Verb Agreement". The respondents had over 50\% correct response on all the items except item 3 which got 3.3\%. The mean scores for correct response and incorrect response are 58.3\% and $41.7 \%$ respectively. This means that the knowledge of Pidgin English did not impact negatively on the learning of English as a second language. The presence of the adverb "always" caused the distraction that resulted in the abysmal performance in item 3 . This finding has vindicated our agreement with Elugbe (2015) who sees Nigerian Pidgin as being different from other forms of English in Nigeria such as language of "Wakabout" and the language of a soap opera called "Masquerade" as used by Chief Zebrudiah Okorigwe Nwobo (its lead character). We stated ab initio that in this work, we lean on the position of Elugbe (2015) to state that our pidgin of discussion is not "Broken English (BE)" but Nigerian Pidgin (NP). For us, BE comes as a result of attempts by semi-illiterate persons to express themselves in "Standard English" which is botched up by wrong manipulation of words. On the other hand, users of NP do not aspire to use Standard English expressions. Most users of NP are literate users of English as well hence the respondents rather have a positive transfer with regard to the making the difference between "have" and "has". 


\section{Conclusion}

Thus far, the paper has investigated the impact of Pidgin English on the effective learning of English in our research area. Judging from the findings, it is pertinent to note that, the main causes of errors are substitution, transfer and overgeneralization of the rules of the first language, Pidgin English (L1) on English, the (L2). Therefore it is both communicatively and pedagogically correct to note that these impediments of the learning of the English language by the junior secondary students in Port Harcourt city can be overcome when proper L2 learning strategies are applied, especially when these negative linguistic interferences can be remediated resorting to both needs and error analysis.

\section{References}

Azubuike, I. (2013, September, 9). Pidgin English: A medium for effective communication? Vanguard. Retrieved from: https://www.vanguardngr.com/2013/09/pidgin-english-a-medium-for-effective-communication/

Elugbe, B. (2015). Nigerian pidgin: Some matters arising. In I. Kamalu (Ed). Issues in the study of language and literature: Theory and practice (pp. 428 - 436). Ibadan: Kraft Books.

Gooden, P. (2011). The story of English: How the English language conquered the world. London: Quercus.

Hutchinson, T. \& Waters, A. (2000). English for specific purposes: A learningcentered approach. United Kingdom: University of Cambridge Press

Idris, S.U. (2016).First language interference in the use of English question tags among Nigeria Certificate in Education Hausa students in Federal College of Education, Zaria (Master's thesis). Ahmadu Bello University, Zaria.

Jowitt, D. (1991). Nigerian English usage: An introduction. Lagos: Longman

Jowitt, D. (2009). English language and literature in historical context. Ibadan:Spectrum

Jowitt, D. (2015). The history of the English language: A sketch.In I. Kamalu (Ed). Issues in the study of language and literature: Theory and practice (pp. 118 - 132). Ibadan: Kraft Books.

Koźbiat, S. (2011). Phonological error mapping: An English - Polish contrastive study.

Diffusion(4), 1. Retrieved from https://bcur.org/journals/index.php/Diffusion/article/view/142/123

Labiba, H. (2015). Mother tongue (Hausa) interference on the syntax of second language (English): A case study of UG IV students of English Language (UndergraduateResearchProject). Usmanu Danfodiyo University, Sokoto

Mahe, Z. \& Adegboye, O.O. (2017). The case of prepositions in some selected schools in Bauchi State. Nile Journal of English Studies(3),4.

Marcus, P.B. (2018). Mother tongue interference on the spoken English of Berom speaking students in Plateau State Polytechnic. IOSR Journal of Humanities and Social Science (23),9,43-47

Ndimele, O. (2011). (Ed.) Orthographies of Nigerian languages manual X. Lagos: Nigerian Educational Research \& Development Council.

Ndiyo, N. A. (2015).Fundamental of research in behavioural sciences and humanities. Calabar: Excel Publishers

Nwala, M.A. \& Obisike, I.O. (2014). Aspects of the English grammar. Port Harcourt: Obisco

Richards, J., Platt, J. \& Weber, H. (1985). Longman dictionary of appliedlinguistics. Great Britain: The Chaucer Press.

Richards, J.C. \& Schmidt, R. (2010). Longman dictionary of language teaching \& applied linguistics $\left(4^{\text {th }}\right.$ ed.).London: Pearson

Shormani, M. Q. \& AlSohbani, Y. A. (2015). Phonological transfer and universal grammar: evidence from Arabic. Journal of Teaching and Teacher Education (3), 2. Retrieved from ww.researchgate.net/publication/285860136_Phonological_Transfer_and_Uni.

Stevenson, A. \& Waite, M. (2011). Concise Oxford English dictionary $\left(12^{\text {th }}\right.$ ed.). London: Oxford Press 